\title{
Kontrol Laju Alir Pompa Air Berpenggerak Brushless DC Motor
}

\author{
Arista Ainurrohmah, Muhammad Rivai, dan Tasripan \\ Departemen Teknik Elektro, Fakultas Teknik Elektro, \\ Institut Teknologi Sepuluh Nopember (ITS) \\ E-mail:muhammad_rivai@ee.its.ac.id
}

\begin{abstract}
Abstrak-Saat ini telah banyak dikembangkan sistem irigasi menggunakan tenaga matahari. Hal ini lebih diminati karena memanfaatkan energi alternatif dari alam. Namun penggunaan energi tersebut tidak efektif karena pada sistem irigasinya masih menggunakan pompa air listrik berpenggerak motor induksi yang membutuhkan arus bolak-balik (AC), sehingga dibutuhkan inverter untuk mengkonversi tegangan searah (DC) menjadi tegangan AC. Pada penelitian ini telah dilakukan rancang bangun untuk mengontrol laju aliran pompa air berpengerak Brushless DC motor (BLDC). Laju alir pompa air dibuat konstan dengan mengatur kecepatan putar motor BLDC menggunakan kontrol Proportional-Integral-Derivative (PID) yang terdeteksi dari sensor hall-effect. Laju alir pompa air akan terbaca oleh sensor water flow yang kemudian akan dibandingkan nilainya dengan nilai yang telah ditentukan sebagai nilai setpoint. Sistem ini diintegrasikan menggunakan mikrokontroler Arduino Due. Pada hasil pengujian keseluruhan sistem menunjukkan bahwa apabila diberikan beban berupa putaran kran pada sistem didapatkan laju aliran air yang stabil dan mendekati nilai setpoint yaitu dengan nilai rata - rata error nya mencapai $0.9 \%$. Sistem ini dapat mempertahankan laju aliran air yang konstan mendekati nilai setpoint.
\end{abstract}

Kata Kunci- Kontroler PID, Mikrokontroler Arduino Due, Motor BLDC, Sensor Flow Rate.

\section{PENDAHULUAN}

A ir merupakan bahan alam yang menjadi kebutuhan utama makhluk hidup. Air sebagai media untuk mengangkut zat-zat makanan, serta merupakan sumber energi dan kebutuhan utama untuk berbagai keperluan [1]. Salah satu keperluan makhluk hidup yang menjadikan air sebagai kebutuhan utama yaitu pada bidang pertanian atau perkebunan [2]. Pemberian air pada pertanian harus pada kondisi, ruang dan waktu yang tepat atau biasa disebut sistem irigasi [3].

Saat ini sistem irigasi yang banyak dikembangkan yaitu sistem irigasi menggunakan tenaga matahari [4],[5],[6]. Sistem irigasi ini dipilih karena matahari merupakan energi yang ramah lingkungan, cocok diletakkan di daerah yang terisolasi listrik dan medan karena pada umumnya ladang petani berada di daerah yang sulit dijangkau [5]. Tenaga surya mengkonversi energi dari radiasi matahari yang kemudian diubah menjadi energi listrik sehingga tidak ada biaya untuk bahan bakarnya. Indonesia merupakan negara tropis dengan tingkat radiasi yang tinggi, sehingga cocok sekali menggunakan tenaga surya sebagai sumber energi terbarukan [7],[8],[9].

Air untuk sistem irigasi harus dapat dikondisikan agar dapat mengalir sesuai kebutuhan. Untuk itu diperlukan sebuah pompa air yang mampu meningkatkan energi kinetik dan potensial pada air. Sistem tenaga surya memiliki output arus searah (DC) sehingga diperlukan pompa air dengan berpenggerak motor DC. Hal ini menguntungkan karena jika pompa air memiliki arus bolak-balik, maka masih dibutuhkan inverter untuk mengonversi tengangannya [4]. Pompa air yang sering digunakan yaitu jenis pompa dengan penggerak motor induksi. Hal ini dikarenakan pada motor induksi pemeliharaannya mudah dan pengaturannya tidak perlu rangkaian elektronika yang rumit. Tetapi motor ini masih memiliki efisiensi yang rendah. Diantara jenis motor listrik saat ini yang memliki efisiensi yang paling tinggi adalah Brushless DC Motor (BLDC) atau motor DC tanpa sikat.

Dibandingkan dengan motor DC konvensional, motor BLDC memiliki kelebihan antara lain, karakteristik kecepatan dan torsi yang lebih baik, tanggapan dinamis yang tinggi, efisiensi tinggi, tahan lama dan rendahnya tingkat noise dibanding dengan motor induksi dan motor DC konvensional [10]. Jika motor BLDC tersebut dijadikan penggerak pompa air, maka akan diperoleh efisiensi yang lebih tinggi daripada motor DC dan dapat diatur kecepatannya sesuai kebutuhan.

Pada penelitian ini telah didesain dan diimplementasikan pompa air listrik dengan berpenggerak motor BLDC. Pengaturan kecepatan putar motor BLDC menggunakan kontrol Proportional-Integral-Derivative (PID) yang dikontrol secara close loop. Laju alir dari pompa air akan terbaca oleh sensor water flow, dimana nilai keluaran sensor akan dibandingkan dengan nilai setpoint dari sistem.

\section{TEORI PENUNJANG}

\section{A. Sensor Water Flow}

Laju alir atau flow rate merupakan cairan bervolume yang bergerak dalam waktu tertentu. Sensor laju alir yaitu suatu alat yang mendeteksi dan mengukur arus air melalui pipa. Ketika air mengalir melewati rotor, maka rotor akan berputar [11]. Dalam sistem ini terdapat sensor hall-effect digunakan untuk menghitung arus rotor yang dikelilingi magnet. Sensor tersebut akan mengeluarkan output pulsa sesuai dengan besarnya aliran air [12]. Struktur Dalam water flow sensor ditunjukkan pada Gambar 1.

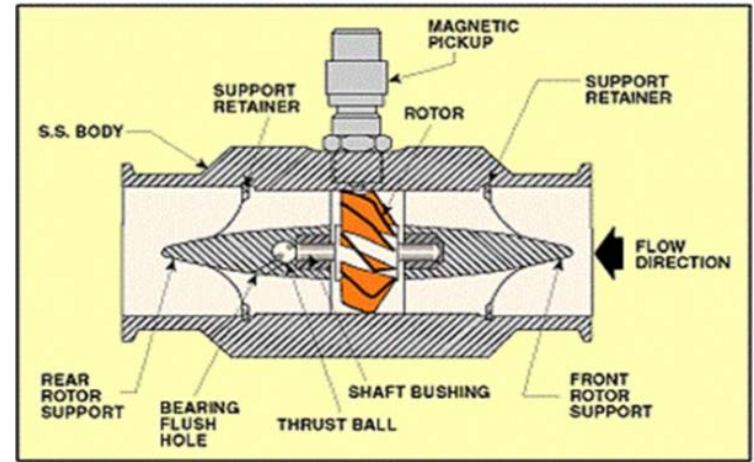

Gambar 1. Struktur dalam sensor Water Flow 


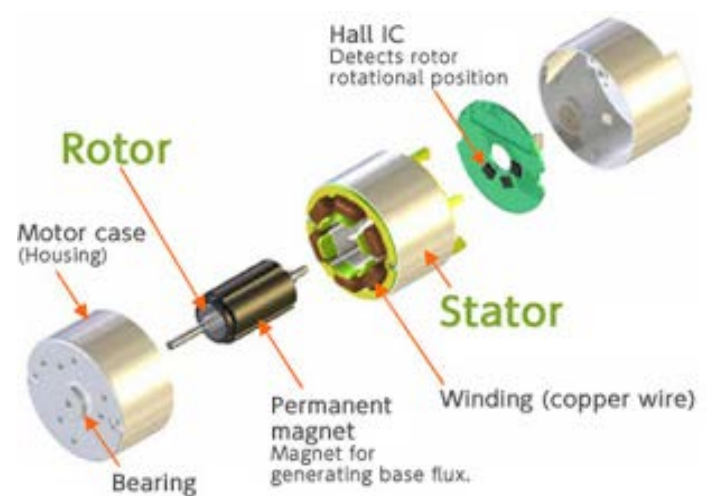

Gambar 2. Konstruksi motor BLDC

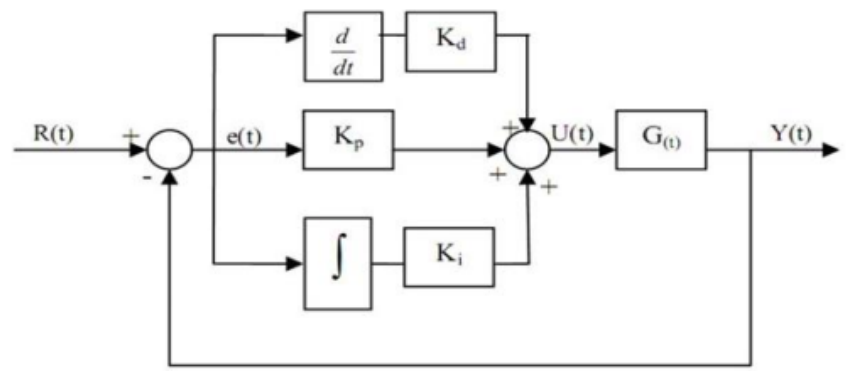

Gambar 3. Diagram blok PID

\section{B. Brushless DC Motor}

Brushless Direct Current (BLDC) motor atau yang sering disebut dengan motor DC tanpa sikat mempunyai permanen magnet pada bagian rotor dan elektromagnet pada bagian stator. Pada motor Brushless DC, pembalikan polaritas dilakukan oleh transistor Switching untuk mensinkronkan posisi rotor [13]. Kebanyakan motor BLDC menggunakan belitan 3 fase dengan topologi Y (star) yang digerakkan dengan mengaktifkan dua fase secara bersamaan [14]. Konstruksi motor BLDC ditunjukkan pada Gambar 2.

\section{Kontrol PID}

Penggunaan PID sebagai sistem kontrol pada industri sudah banyak dilakukan [15]-[18]. Sistem kontrol Proportional-Integral-Derrivative (PID) adalah kontroler untuk menentukan presisi suatu sistem instrumentasi dengan umpan balik pada sistem tersebut (feedback). Kontrol PID dapat menghasilkan sinyal yang sebanding dengan sinyal error (proporsional), sebanding dengan total sinyal error (integral), dan sebanding dengan penurunan dari sinyal error yang sekarang dengan sebelumnya (derivative)[19]. Sinyal error adalah selisih dari setpoint dengan nilai keluaran aktual. Kontrol PID akan diimplementasikan menggunakan Arduino DUE [20]. Blok diagram kontrol PID dapat dilihat pada Gambar 3.

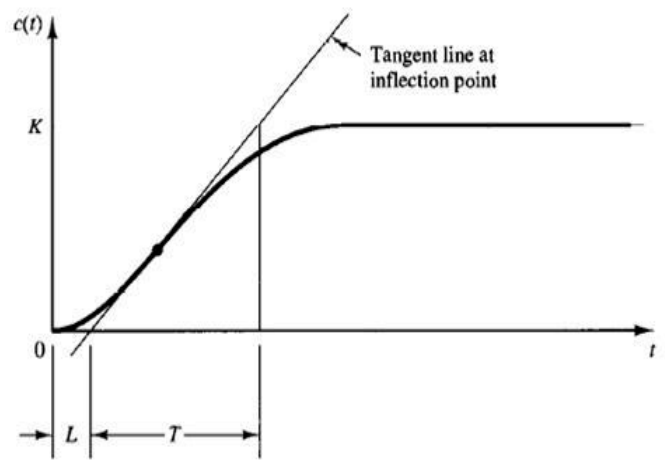

Gambar 4. Penentuan parameter PID
Tabel 1.

FORMULA ZIEGLER-NICHOLS PADA METODE OPEN LOOP

\begin{tabular}{lccc}
\hline Tipe Pengendali & $\mathbf{K p}$ & $\mathbf{K i}$ & Kd \\
\hline P & $\frac{T}{L}$ & $\infty$ & 0 \\
PI & $\frac{0.9 T}{L}$ & $0.27 \frac{T}{L^{2}}$ & 0 \\
PID & $\frac{1.2 T}{L}$ & $0.6 \frac{T}{L^{2}}$ & $0.6 \mathrm{~T}$ \\
\hline \hline
\end{tabular}

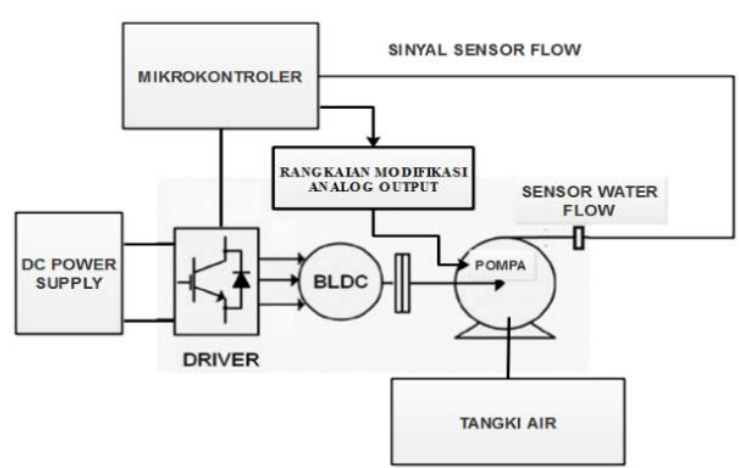

Gambar 5. Diagram blok fungsional sistem

\section{Ziegler Nichols}

Metode Ziegler Nichols digunakan untuk menentukan parameter kontroler PID supaya sistem dapat close loop dan memenuhi kriteria performansi yang telah ditentukan. Metode Ziegler-Nichols ini memiliki dua cara yaitu metode osilasi dan kurva reaksi yang keduanya menghasilkan respon sistem dengan lonjakan maksimum sebesar 25\%[21]. Metode kurva reaksi didasarkan terhadap reaksi sistem open loop yang memiliki aturan perpotongan garis kurva S pada grafik output plant ketika diberi input unit step yang mempengaruhi nilai $\mathrm{T}$ dan $\mathrm{L}$ seperti pada Gambar 4. setelah nilai $\mathrm{T}$ dan $\mathrm{L}$ diketahui, maka dengan menggunakan formula yang telah di rumuskan pada Tabel 1 , nilai Kp, Ki, dan Kd yang optimal untuk sistem dapat diketahui[17].

\section{PERANCANGAN SISTEM}

\section{A. Blok Fungsional Sistem}

Gambar 5 menunjukkan diagram blok fungsional sistem yang dapat mengontrol laju aliran pompa air agar dapat mengairi tanaman sesuai kebutuhan. Pada sistem ini akan digunakan pompa air dengan berpenggerak motor BLDC yang bertujuan agar kinerja sistem lebih efisien. Perputaran motor BLDC akan dikontrol menggunakan driver motor yang telah diintegrasikan dengan mikrokontroler Arduino DUE. Aliran air dari pompa akan terbaca oleh sensor water flow dan datanya akan dikirimkan ke mikrokontroler untuk di proses. Laju aliran air akan dibuat konstan sehingga data yang terbaca akan dibandingkan dengan setpoint untuk dapat disesuaikan dengan nilai yang telah ditentukan. Dikarenakan pompa air menggunakan motor BLDC sebagai penggeraknya, maka dibutuhkan power supply jenis DC sebagai catu daya sistem. Hasil perancangan sistem pompa air ditunjukkan pada Gambar 6.

\section{B. Rangkaian Modifikasi Analog Output Arduino Due}

Pada Arduino Due tidak memiliki tegangan keluaran analog dari $0 \mathrm{~V}$ ke Vref, tetapi dari 1/6 hingga 5/6 dari Vref, yaitu $0,55 \mathrm{~V}$ dan $2,75 \mathrm{~V}$. Rentang tegangan output DAC hanya $2,75-0,55=2,2 \mathrm{~V}$. Sehingga dibutuhkan suatu rangkaian 
diferential amplifier yang dapat menghilangkan tegangan offset $0,55 \mathrm{~V}$ dan menguatkan output sinyal analog. Nilai penguatan dan nilai komponen R1 dan R2 dapat dihitung sebagai berikut.

$$
G=\frac{5}{2.2}=2.27 \Leftrightarrow \frac{R 1}{R 2}
$$

Apabila R1 bernilai $100 \mathrm{~K} \Omega$ maka R2 bernilai $227 \mathrm{~K} \Omega$, dengan VCC dari IC amplifier harus diberi catu daya minimal 7V. Desain rangkaian analog output ditunjukkan pada Gambar 7.

\section{Perancangan Kendali PID}

Perancangan kendali PID digunakan untuk mempertahankan laju aliran air tetap pada keadaan konstan, dimana nilai debit yang akan dibuat konstan digunakan sebagai nilai setpoint. Nilai setpoint akan ditambahkan dengan nilai PID sehingga akan menghasilkan output DAC yang digunakan untuk mendrive motor BLDC. Nilai DAC tersebut telah dikonversi menjadi tegangan sehingga dapat terbaca oleh Electronic Speed Controler (ESC.) Error dari kendali PID debit didapatkan dari selisih antara setpoint debit yang diinginkan dengan debit yang didapatkan dari pembacaan sensor flow. Nilai error tersebut kemudian akan ditambahkan dengan nilai PID sehingga didapatkan nilai debit yang konstan (sama atau mendekati nilai debit setpoint). Proses kalkulasi tersebut akan dilakukan oleh mikrokontroler Arduino DUE. Blok diagram kontrol PID debit dapat dilihat pada Gambar 8.

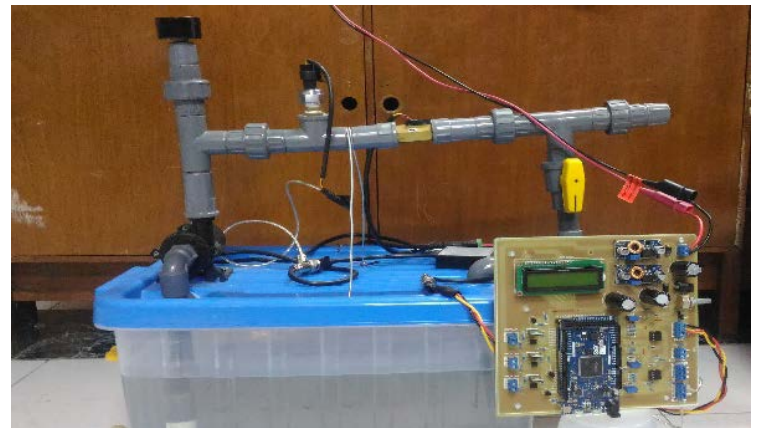

Gambar 6. Hasil perancangan sistem pompa air

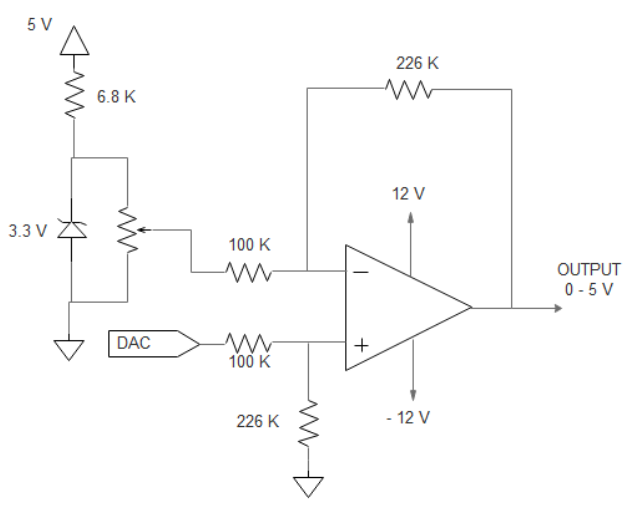

Gambar 7. Rangkaian modifikasi analog output

\section{Perancangan Kontrol Sistem}

Diagram alur sistem dimulai dengan inisialisasi sensor yang digunakan pada sistem yaitu sensor water flow. Agar sensor water flow dapat terbaca dengan tepat, maka diberikan nilai setpoint sebagai data pembanding pada sistem. Kemudian sensor water flow akan membaca laju aliran air, dan dengan menggunakan kendali PID laju aliran air akan di kontrol agar tetap konstan ketika laju alir ditambah atau dikurang. Jika nilai debit yang terbaca kurang dari setpoint, maka dengan kontrol PID nilai debit air akan ditambah hingga sama atau mendekati nilai setpoint. Sebaliknya, jika nilai debit lebih yang terbaca lebih besar dari nilai setpoint, maka kontrol PID kan mengurangi nilai debit hingga sama atau mendekati dengan nilai setpoint. Selanjutnya nilai dari pembacaan sensor water flow yang berupa debit dan telah dikontrol dengan kendali PID akan ditampilkan ke LCD sebagai pembacaan akhir dari sensor. Flowchart kontrol sistem ditunjukkan pada Gambar 9.

\section{HASIL IMPLEMENTSI SISTEM}

\section{A. Pengujian Rangkaian Modifikasi Analog Output Arduino Due}

Pengujian rangkaian modifikasi analog output dilakukan dengan mengukur tegangan input pada pin DAC0 dan tegangan output dari opamp dengan input nilai DAC yang diberikan pada pin DAC0. Rangkaian modifikasi analog output digunakan untuk merubah tegangan output analog yaitu dari 0 - $3.3 \mathrm{~V}$ menjadi 0 - $5 \mathrm{~V}$ saat diberi nilai DAC dari 0 - 255. Tabel pengujian rangkaian modifikasi analog output ditunjukkan pada Tabel 2.

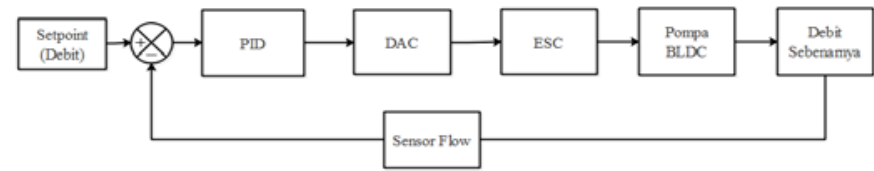

Gambar 8. Blok diagram kontrol PID untuk debit

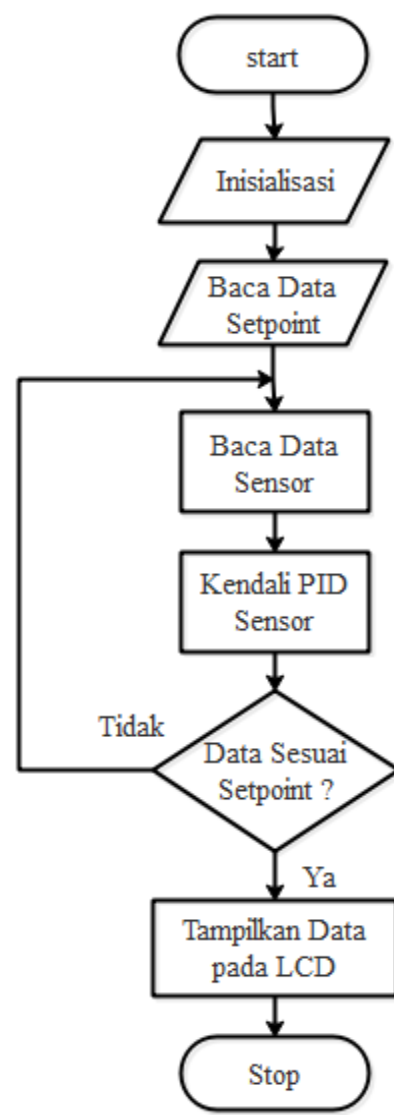

Gambar 9. Flowchart kontrol sistem

Tabel 2.

Pengujian Rangkaian Modifikasi Analog Output Arduino Due

\begin{tabular}{ccc}
\hline \hline Nilai DAC & Vin & Vout \\
\hline 0 & 0.57 & 0.0073 \\
50 & 1.006 & 0.943 \\
100 & 1.444 & 1.882 \\
150 & 1.968 & 3.008 \\
250 & 2.755 & 4.7 \\
\hline \hline
\end{tabular}


Tabel 3.

Pengujian sensor water flow

\begin{tabular}{cc}
\hline \hline Air (Liter) & Sensor Water Flow \\
\hline 3 & 21 \\
9 & 85 \\
11 & 108 \\
13 & 121 \\
17 & 167 \\
\hline \hline
\end{tabular}

Tabel 4.

Data karakterisasi sensor water flow

\begin{tabular}{ccccc}
\hline \hline $\begin{array}{c}\text { Nilai } \\
\text { DAC }\end{array}$ & $\begin{array}{c}\text { Volume } \\
(\mathbf{L})\end{array}$ & $\begin{array}{c}\text { Waktu } \\
(\mathbf{M})\end{array}$ & $\begin{array}{c}\text { Frekuensi } \\
(\mathbf{H z})\end{array}$ & $\begin{array}{c}\text { Debit Pengukuran } \\
(\mathbf{L} / \mathbf{M})\end{array}$ \\
\hline 50 & 10 & 2.16 & 42 & 4.63 \\
130 & 10 & 1.15 & 85 & 8.7 \\
150 & 10 & 0.96 & 98 & 10.42 \\
210 & 10 & 0.71 & 136 & 14.08 \\
255 & 10 & 0.56 & 168 & 17.86 \\
\hline \hline
\end{tabular}

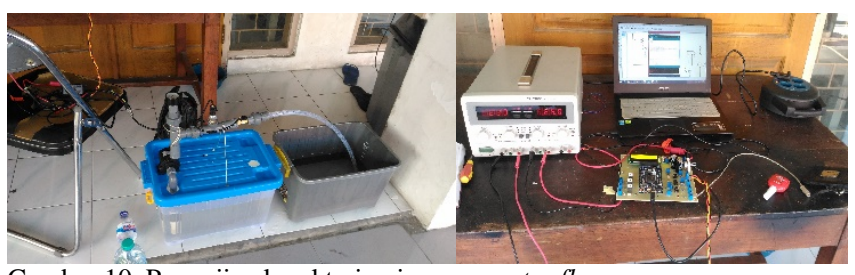

Gambar 10. Pengujian karakterisasi sensor water flow

\section{B. Pengujian Sensor Water Flow}

Pengujian sensor water flow dilakukan dengan tujuan untuk mengetahui berapa pulsa yang dikeluarkan ketika air mengalir dalam beberapa liter. Pengujian sensor water flow ini dilakukan dengan cara mengalirkan air (per liter) dan air tersebut melewati sensor water flow. Pengujian tersebut dapat dilihat pada Tabel 3.

\section{Karakterisasi Sensor Water Flow}

Sebelum digunakan dalam sistem kontrol laju alir, sensor water flow hendaknya dikalibrasi terlebih dahulu, supaya sistem dapat bekerja secara maksimal. Pengkalibrasian sensor water flow dilakukan dengan cara mengalirkan air (per 10 liter) melewati sensor water flow, kemudian mencatat waktu nya ketika diberi input nilai DAC yang diubah-ubah, sehingga dari data tersebut nilai debit aliran dapat ditentukan. Cara kalibrasi sensor water flow ditunjukkan pada Gambar 10. Pada Tabel 4 dapat dilihat bahwa pada data karakterisasi sensor water flow didapatkan nilai debit yang terus bertambah ketika nilai DAC juga ditambah. Keadaan ini mengindikasikan bahwa semakin besar nilai DAC, maka kecepatan motor akan semakin besar.

Tabel 5.

\begin{tabular}{cccc}
\multicolumn{4}{c}{ Parameter Kontrol PID } \\
\hline \hline P & KP & KI & KD \\
PI & 5 & - & - \\
PID & 6.5 & 0.0216 & - \\
\hline \hline
\end{tabular}

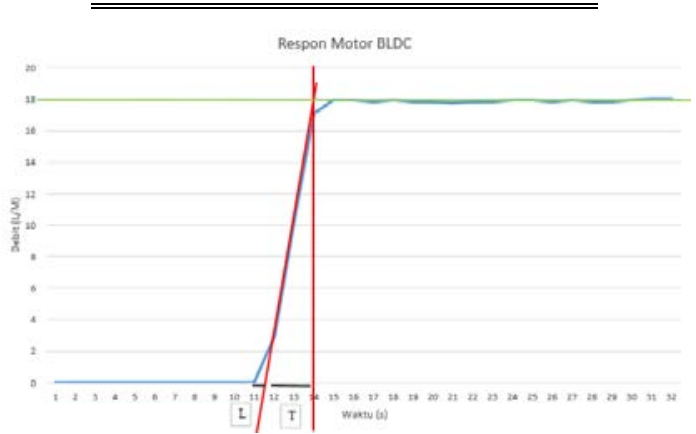

Gambar 11. Analisa Respon Motor BLDC Menggunakan Metode Ziegler Nichols.

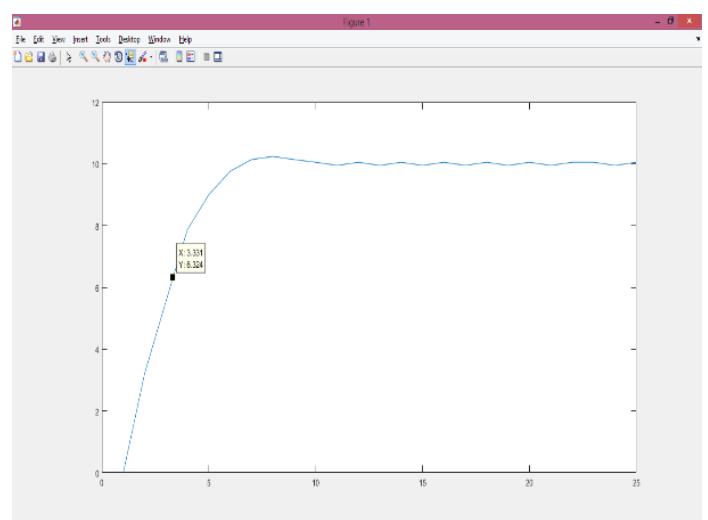

Gambar 12. Respon pengujian sistem secara keseluruhan

$$
\operatorname{Debit}(Q)=\frac{\text { Volume Aliran }(\text { Liter })}{\text { Waktu Aliran }(\text { Menit })}
$$

\section{Pengujian Motor BLDC}

Pengujian motor BLDC digunakan untuk mendapatkan nilai PID yang dilakukan dengan mengambil karakterisasi respon dari motor BLDC. Pengujian motor ini dilakukan secara open loop. Pengujian motor BLDC ini dilakukan dengan melihat perubahan respon motor BLDC, dari nilai debit minimum yaitu 0 L/M hingga mencapai nilai maksimum yaitu 18 L/M. Setelah didapatkan grafik respon motor BLDC, dengan menggunakan metode Ziegler Nichols untuk menghitung parameter PID menggunakan rumus seperti pada Tabel 2. 2. Seperti yang ditunjukkan pada Gambar 11, nilai L yang didapatkan dari respon motor BLDC yaitu 0,5 dan nilai $T$ nya yaitu 2,5 . Sehingga akan didapatkan nilai Kp, Ki, dan Kd Seperti pada Tabel 5.

\section{E. Pengujian Kestabilan Sistem}

Pengujian kestabilan sistem bertujuan untuk melihat respon sistem seperti yang ditunjukkan pada Gambar 12. Respon pengujian ini akan di analisa menggunakan karakteristik respon waktu agar dapat diketahui performansi sistemnya, pada saat nilai debit setpoint sebesar $10 \mathrm{~L} / \mathrm{M}$. Hasil respon pengujian sistem dapat dinyatakan fungsi alih respon motor BLDC nya sebagai berikut. Dimana K adalah gain overall dan $\tau$ adalah konstanta waktu.

- $\quad K=\frac{y_{s s}}{x_{s s}}=\frac{10.01}{9.95}=1.01$

- $\tau=3.31$

$$
\frac{y_{(s)}}{x_{(s)}}=\frac{K}{\tau s+1}=\frac{1.01}{3.31 s+1}
$$

Tabel 6.

Pengujian efisiensi sistem

\begin{tabular}{cccccc}
\hline \hline \multirow{2}{*}{$\begin{array}{c}\text { Waktu } \\
\text { (Hour) }\end{array}$} & $\begin{array}{c}\text { Voltage } \\
\text { (V) }\end{array}$ & $\begin{array}{c}\text { Arus } \\
\text { (A) }\end{array}$ & $\begin{array}{c}\text { Daya } \\
\text { (Watt) }\end{array}$ & $\begin{array}{c}\text { Debit yang } \\
\text { Terukur } \\
(\mathbf{L} / \mathbf{M})\end{array}$ & $\begin{array}{c}\text { Suhu } \\
\left({ }^{\mathbf{0}} \mathbf{C}\right)\end{array}$ \\
\hline 0,5 & 24 & 1,54 & 36,96 & 15,02 & 39,0 \\
1 & 24 & 1,54 & 36,96 & 15,02 & 39,8 \\
1,5 & 24 & 1,54 & 36,96 & 15,02 & 40,6 \\
2 & 24 & 1,54 & 36,96 & 15,02 & 40,8 \\
2,5 & 24 & 1,54 & 36,96 & 15,02 & 41,1 \\
3 & 24 & 1,54 & 36,96 & 15,02 & 41,5 \\
3,5 & 24 & 1,54 & 36,96 & 15,02 & 42,0 \\
4 & 24 & 1,54 & 36,96 & 15,02 & 42,1 \\
4,5 & 24 & 1,54 & 36,96 & 15,02 & 42,3 \\
5 & 24 & 1,54 & 36,96 & 15,02 & 42,6 \\
5,5 & 24 & 1,54 & 36,96 & 15,02 & 42,4 \\
6 & 24 & 1,54 & 36,96 & 15,02 & 42,5 \\
\hline \hline
\end{tabular}


Tabel 7.

Pengujian Sistem dengan Beban Menggunakan PID

\begin{tabular}{cccc}
\hline $\begin{array}{c}\text { Sudut } \\
\left.\mathbf{(}^{(}\right)\end{array}$ & $\begin{array}{c}\text { Debit yang } \\
\text { Ditentukan }(\mathbf{L} / \mathbf{M})\end{array}$ & $\begin{array}{c}\text { Debit yang } \\
\text { Terukur }(\mathbf{L} / \mathbf{M})\end{array}$ & $\begin{array}{c}\text { Error } \\
(\%)\end{array}$ \\
\hline 0 & 5 & 5 & 0 \\
10 & 5 & 4.99 & 0.2 \\
20 & 5 & 4.98 & 0.4 \\
30 & 5 & 4.96 & 0.8 \\
40 & 5 & 4.95 & 1 \\
50 & 5 & 4.94 & 1.2 \\
60 & 5 & 4.86 & 2.8 \\
\hline \hline
\end{tabular}

Hasil respon pengujian kestabilan sistem tersebut juga dapat ditentukan karakteristik respon transient sistem orde pertamanya yaitu rise time, time delay dan settling time. Nilai rise time atau waktu naik yang diukur saat respon mencapai $5 \%$ - 95\% dari steady state.

$$
\begin{aligned}
t_{r}(5 \%-95 \%) & =\tau \ln 19 \\
& =3.31(\ln 19) \\
& =9.74
\end{aligned}
$$

Nilai time delay atau waktu tunda diukur saat respon mencapai $50 \%$ dari keadaan steady state. Nilai tersebut merupakan nilai keterlambatan respon akibat proses sampling.

$$
\begin{aligned}
t_{d}=t_{50 \%} & =\tau \ln 2 \\
& =3.31(\ln 2) \\
& =2.29
\end{aligned}
$$

Sedangkan nilai settling time atau waktu tunak diukur saat respon mencapai 5\% dari keadaan steady state.

$$
\begin{aligned}
t_{s}=t(5 \%) & =\tau \ln 20 \\
& =3.31(\ln 20) \\
& =9.91
\end{aligned}
$$

Pengimplementasian PID pada sistem dapat dikatakan berhasil dengan mengukur besarnya kesalahan pada keadaan tunak atau error steady state. Perhitungan nilai error steady state yaitu besarnya kesalahan pada keadaan tunak, dapat dilihat sebagai berikut.

$$
\begin{aligned}
\% \varepsilon_{\text {ss }} & =(1-K) \times 100 \% \\
& =(1-1.01) \times 100 \% \\
& =1 \%
\end{aligned}
$$

Tabel 8.

Pengujian sistem dengan beban tanpa menggunakan PID

\begin{tabular}{cccc}
\hline \hline Sudut $\left.\mathbf{(}^{\mathbf{0}}\right)$ & $\begin{array}{c}\text { Debit yang } \\
\text { Ditentukan (L/M) }\end{array}$ & $\begin{array}{c}\text { Debit yang Terukur } \\
(\mathbf{L} / \mathbf{M})\end{array}$ & $\begin{array}{c}\text { Error } \\
(\mathbf{\%})\end{array}$ \\
\hline 0 & 5 & 5.04 & 0.8 \\
10 & 5 & 4.99 & 0.2 \\
20 & 5 & 4.71 & 5.8 \\
30 & 5 & 4.72 & 5.6 \\
40 & 5 & 3.88 & 22.4 \\
50 & 5 & 2.34 & 53.2 \\
60 & 5 & 1.27 & 74.6 \\
\hline \hline
\end{tabular}

\section{F. Pengujian Efisiensi Sistem}

Perubahan air dari diam menjadi bergerak memiliki energi kinektik dan potensial, sehingga pengujian efisiensi sistem dilakukan dengan melihat perbandingan energi yang digunakan untuk mensuplai sistem dengan energi yang berubah yaitu aliran air. Pengujian ini dilakukan dengan menjalankan sistem selama 6 jam. Hasil pengujian didapatkan besar daya rata-rata yaitu 36,48 watt dengan besar aliran air yaitu 15,02 L/M. Pada pengujian ini motor BLDC semakin lama akan bertambah panas suhunya, namun tidak mempengaruhi kinerja dari sistem. Hasil pengujian efisiensi sistem ditunjukkan pada Tabel 6 .

\section{G. Pengujian Sistem Menggunakan Beban}

Pengujian keseluruhan sistem menggunakan beban dilakukan dengan memutar katup kran air yang ada pada sistem dan mencatat besar nilai debit serta melihat respon sistem ketika sudut katup kran diubah. Pengujian ini dilakukan pada saat sistem diberi kontrol dan tanpa diberi kontrol.

Pengujian sistem dengan beban menggunakan PID ditunjukkan pada Tabel 7. Hasil pengujian sistem didapatkan nilai debit yang terukur mendekati nilai setpoint, dengan rata - rata prosentase error-nya yaitu $0.9 \%$. Hasil tersebut membuktikan bahwa penambahan kontrol PID membuat sistem lebih stabil dengan nilai error yang dapat ditoleransi. Sedangkan pengujian sistem dengan beban tanpa menggunakan PID ditunjukkan pada Tabel 8. Pada hasil pengujian sistem didapatkan nilai debit yang terukur menjahui nilai setpoint, yaitu dengan rata - rata prosentase error 23.2\%. Hasil tersebut membuktikan bahwa sistem yang tidak diberi kontroler kinerjanya tidak stabil dan didapatkan nilai nilai error yang besar.

Pada pengujian sistem menggunakan beban dengan PID, laju aliran air dapat kembali ke nilai setpoint ketika sistem diberi hambatan berupa putaran kran air dengan sudut tertentu. Pada Gambar 13 merupakan hasil pengujian sistem menggunakan menggunakan PID saat kran air diputar dari sudut 0 ke 60 derajat. Sedangkan pada pengujian sistem menggunakan beban tanpa menggunakan PID, laju aliran air tidak dapat kembali ke nilai setpoint ketika sistem di beri hambatan berupa putaran kran air dengan sudut tertentu. Pada Gambar 14 merupakan hasil pengujian sistem tanpa menggunakan PID saat kran air diputar dari sudut 0 ke 60 derajat.

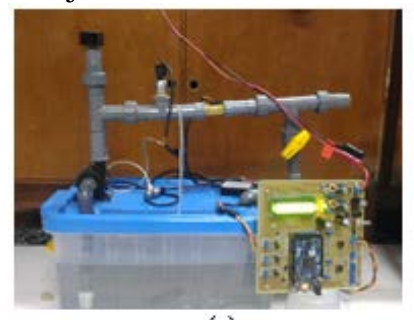

(a)

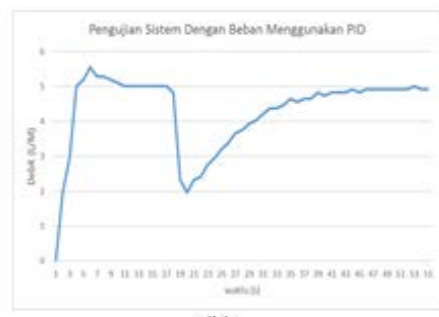

(b)
Gambar 13. Pengujian sistem dengan beban menggunakan PID saat sudut 0 ke 60 derajat (a) Cara pengujian (b) Grafik hasil pengujian

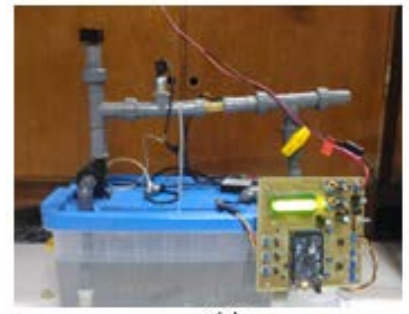

(a)

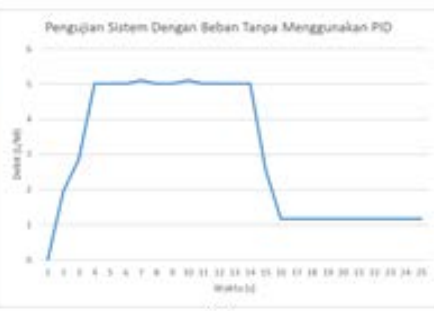

(b)
Gambar 14. Pengujian sistem dengan beban tanpa PID saat sudut 0 ke 60 derajat (a) Cara pengujian (b) Grafik hasil pengujian

\section{KESIMPULAN}

Hasil dari perancangan sistem serta pengukuran dari sistem kontrol laju alir pompa air berpenggerak brushless DC motor, dapat diambil kesimpulan bahwa laju alir dapat mempertahankan alirannya untuk tetap konstan. Pada keseluruhan sistem menggunakan PID apabila diberikan beban berupa putaran kran didapatkan laju aliran air yang stabil dan mendekati nilai setpoint dengan error maksimum 2.8\% Sedangkan pada keseluruhan sistem tanpa 
menggunakan PID apabila diberikan beban berupa putaran kran didapatkan laju aliran air yang tidak stabil dan menjahui nilai setpoint dengan error maksimum $74.6 \%$.

\section{DAFTAR PUSTAKA}

[1] E. B. Sasongko, E. Widyastuti, and R. E. Priyono, "Kajian kualitas air dan penggunaan sumur gali oleh masyarakat disekitar sungai kaliyasa kabupaten cilacap,” J. Ilmu Lingkung., vol. 12, no. 2, pp. 72-82, Oct. 2014.

[2] M. Dzulkifli S., M. Rivai, and S. Suwito, "Rancang Bangun Sistem Irigasi Tanaman Otomatis Menggunakan Wireless Sensor Network," vol. 5, Jan. 2016

[3] A. Ansori, A. Ariyanto, and Syahroni, "Kajian Efektifitas dan Efisiensi Jaringan Irigasi Terhadap Kebutuhan Air pada Tanaman Padi (Studi Kasus Irigasi Kaiti Samo Kecamatan Rambah Kabupaten Rokan Hulu),” Progr. Stud. Tek. Sipil, UPP.

[4] P. Wulandari, "Rancang bangun prototip sistem pompa air mengambang bertenaga surya untuk irigasi tanaman,” Universitas Muhammadiyah Surakarta, 2017.

[5] W. M. Ziwangga, W. I. Basori, and D. C. Happyanto, "Rancang Bangun Sistem Kontrol Irigasi Cerdas Tenaga Surya Untuk Mengatasi Kekeringan Pertanian Cabai di Pegunungan Blitar Selatan,” J. Innov. Technol. Compet., p. 28, 2014.

[6] P. Widodo and D. A. Nasution, "Rekayasa disain pompa tenaga surya untuk irigasi budidaya bawang merah di lahan kering,” in Prosiding Seminar Nasional Teknologi Pertanian, 2016, vol. 0, no. 0.

[7] A. A. J. Fahiswara, M. Ashari, and H. Suryoatmojo, Desain dan Simulasi Sistem Pompa Air Sel Surya dengan Optimasi Kontrol Slip Untuk Memaksimalkan Daya dan Efisiensi, vol. Tugas Akhir. Surabaya: Teknik Elektro, ITS, 2015.

[8] B. Hartono and Purwanto, "Perancangan Pompa Air Tenaga Surya Guna Memindahkan Air Bersih ke Tangki Penampung,” J. SINTEK, vol. 9 No 1, pp. 28-33.

[9] A. I. Ramadhan, E. Diniardi, and S. H. Mukti, “Analisis desain sistem pembangkit listrik tenaga surya kapasitas 50 WP,” Teknik, vol. 37, no. 2, pp. 59-63, Dec. 2016.

[10] R. Aditya, W. Putra, E. Firmansyah, and F. Danang Wijaya, "Metode six step comutation pada perancangan rangkian kendali sensored motor brushless direct current,” J. Penelit. Tek. Elektro dan Tek. Inf., vol. 1, no. 1, pp. 46-50, 2014.
[11] A. Suharjono, L. N. Rahayu, and R. Aofwah, "Aplikasi Sensor Flow Water Untuk Mengukur Penggunaan Air Pelanggan Secara Digita Serta Pengiriman Data Secara Otomatis Pada PDAM Kota Semarang,” J. TELE, vol. 13 No 1, pp. 7-12, Mar. 2015.

[12] R. Sood, M. Kaur, and H. Lenka, "Design and Development of Automatic Water Flowmeter,” Int. J. Comput. Sci. Eng. Appl., vol. 3, no. 3, pp. 49-59, Jun. 2013.

[13] L. N. Elevich, 3-Phase BLDC Motor Control with Hall Sensors Using 56800/E Digital Signal Controllers, 2nd ed. Freescale Semiconductor, Inc., 2005.

[14] M. H. Rashid, Ed., Power electronics handbook: devices, circuits, and applications, 3. ed. Amsterdam: Elsevier/BH, ButterworthHeinemann, 2011.

[15] F. Lin, H. Duan, and X. Qu, "PID control strategy for UAV flight control system based on improved genetic algorithm optimization," in The 26th Chinese Control and Decision Conference (2014 CCDC), 2014, pp. 92-97.

[16] V. Indragandhi, R. Selvamathi, and T. Arunkumari, "Speed control of a switched reluctance motor using PID controller for PV based water pumping applications,” in 2017 Innovations in Power and Advanced Computing Technologies (i-PACT), 2017, pp. 1-4.

[17] A. A. Kurniawan, M. Rivai, and F. Budiman, "Sistem pemandu pendaratan pada balon udara berbasis pengolahan citra dan kendali PID,” J. Tek. ITS, vol. 5, no. 2, pp. A179-A184, Aug. 2016.

[18] M. Rivai, M. Suwito, P. Chondro, and S.-J. Ruan, "Design and implementation of a submerged capacitive sensor in PID controller to regulate the concentration of non-denatured ethyl alcohol,” in 2015 International Seminar on Intelligent Technology and Its Applications (ISITIA), 2015, pp. 45-50.

[19] P. D. Wijaya, M. Rivai, T. Tasripan, and T. Tasripan, "Rancang bangun mesin pemotong styrofoam 3 axis menggunakan hot cutting pen dengan kontrol PID,” J. Tek. ITS, vol. 6, no. 2, pp. A693-A698, Oct. 2017.

[20] A. D. S. Gaviola, M. Rivai, and H. Kusuma, "Audio beam steering with phased array method using Arduino Due Microcontroller,” in International Conference on Information and Communications Technology (ICOIACT), 2018, pp. 597-600.

[21] H. Wicaksono, “Analisa Performansi dan Robustness Beberapa Metode Tuning Kontroler PID pada Motor DC,” J. Tek. Elektro, UK Petra, vol. 4 No.2, Sep. 2004. 